\title{
Study of Coxsackie B viruses interactions with Coxsackie Adenovirus receptor and Decay-Accelerating Factor using Human $\mathrm{CaCo}-2$ cell line
}

Samira Riabi ${ }^{1,2^{*}}$, Rafik Harrath $^{1,2+}$, Imed Gaaloul ${ }^{1}$, Lamjed Bouslama ${ }^{3}$, Dorsaf Nasri ${ }^{2}$, Mahjoub Aouni', Sylvie Pillet ${ }^{4}$ and Bruno Pozzetto 2,4

\begin{abstract}
Background: Decay Accelerating Factor (DAF) and Coxsackievirus-Adenovirus Receptor (CAR) have been identified as cellular receptors for Coxsackie B viruses (CV-B). The aim of this study is to elucidate the different binding properties of CV-B serotypes and to find out if there are any amino acid changes that could be associated to the different phenotypes.

Twenty clinical CV-B isolates were tested on CaCo-2 cell line using anti-DAF (BRIC216) and anti-CAR (RmcB) antibodies. CV-B3 Nancy prototype strain and a recombinant strain (Rec, CV-B3/B4) were tested in parallel. The P1 genomic region of $12 \mathrm{CV}$-B isolates from different serotypes was sequenced and the Trans-Epithelial Electrical Resistance (TEER) along with the virus growth cycle was measured.

Results: Infectivity assays revealed clear differences between CV-B isolates with regard to their interactions with DAF and CAR. All tested CV-B isolates showed an absolute requirement for CAR but varied in their binding to DAF. We also reported that for some isolates of CV-B, DAF attachment was not adapted. Genetic analysis of the P1 region detected multiple differences in the deduced amino acid sequences.
\end{abstract}

Conclusion: Within a given serotype, variations exist in the capacity of virus isolates to bind to specific receptors, and variants with different additional ligands may arise during infection in humans as well as in tissue culture.

Keywords: CV- B, CaCo-2 cell line, Receptors, Phenotypes, Variants, TEER

\section{Background}

The six serotypes of coxsackie B viruses (CVB1- 6) are members of the Human enterovirus B (HEV-B) species of the Enterovirus genus within the Picornaviridae family. They are causative agents of a broad spectrum of clinically relevant diseases including acute and chronic myocarditis, meningitis and possibly autoimmune diabetes [1-3]. The $7.4 \mathrm{~kb}$ positive stranded RNA genome of CV-B consists of a 5_untranslanslated region (5_UTR) followed by a single

\footnotetext{
* Correspondence: riabi_samira@yahoo.fr

${ }^{\dagger}$ Equal contributors

'Laboratory of Transmissible Diseases LR99-ES27, Faculty of Pharmacy, Avenue Avicenne 5000, Monastir, Tunisia

2Laboratory of Bacteriology-Virology, GIMAP EA3064, Faculty of Medicine of Saint-Etienne, Saint-Etienne, France

Full list of author information is available at the end of the article
}

polyprotein coding region and a 3_UTR, flanked by a poly A-tail [4]. The first part of the polyprotein (P1) encodes the four capsid proteins, and the second and third part of the polyprotein (P2 and P3, respectively) encode nonstructural proteins involved in genome processing and RNA synthesis [5]. The four capsid proteins, VP1-VP4, assemble into a pseudo $-\mathrm{T}=3$ icosahedral capsid. The VP1-VP3 make up the outer surface of the viral particle, while VP4 is embedded within the inner surface of the capsid [5]. A prominent feature of the capsid surface is a small depression surrounding the fivefold axis, the socalled "canyon" which is proposed to enable virus attachment by interaction with cell surface molecules $[6,7]$. Receptor binding induces conformational changes which facilitate the release of viral RNA into host cells $[8,9]$. 
The identification of specific cellular receptors and viral receptor-binding sites are among the major goals of fundamental virology. To date, two types of cellular molecules have been identified as cell surface receptors for CV-B. CAR is a $46 \mathrm{kDa}$ membrane glycoprotein and part of a larger protein complex in the tight junction of the cell and might function as a cell-cell adhesion molecule [10-12]. In both polarized cells and mucosal epithelium, the CAR protein is absent from the apical surface and is localized to intercellular tight junctions $[13,14]$. CARnegative and nonpolarized cells are considered to be non permissive for CV-B infection in vitro. Additionally, CV-B serotypes 1,3 , and 5 have been found to bind Decay-Accelerating Factor (DAF/CD55) as a co-receptor [9,15-17]. DAF, a $70 \mathrm{kDa}$ glycosylphosphatidylinositolanchored membrane protein, is a member of the regulators of complement activation (RCA) family that regulate complement activation by binding to and accelerating the decay of convertases, the central amplification enzymes of the complement cascade [18]. DAF functional region consists of four short consensus repeats (SCR1 to 4) $[16,17,19]$. This protein was also described as a receptor for echoviruses, Enterovirus 70, and Coxsackievirus A 21 [20-22]. Although DAF binding is likely to facilitate viral adsorption and mediate tropism, the availability of DAF receptor molecules on the host seems to be insufficient to facilitate cell entry and lytic infection of CV-B even to the DAF-adapted strains $[16,17,23]$. Upon transfection with CAR cDNA, non-infectable hamster $\mathrm{CHO}$ cells become susceptible to infection with CV-B [24,25]. Moreover, even $\mathrm{CV}-\mathrm{B}$ strains with strong DAF-binding properties require the CAR protein to mediate lytic infection [23-26]. Therefore, it appears that DAF and CAR capacities to impart permissiveness to infection are not equivalent. Virus interaction with CAR, but not with DAF, leads to a post attachment event that is essential for infection to proceed. During eclipse, enterovirus capsids undergo conformational changes that lead to the release of viral RNA into the cytoplasm [27]. After attachment, most cell-associated viruses are converted into an irreversibly altered form, the A particle, which has lost the internal capsid protein VP4, and no longer interacts with cellular receptors or infects receptor-bearing cells [28].

With regard to these findings, the current study was performed to elucidate the CV-B interactions with CAR and DAF receptors on the cell surface. To address this topic, clinical CV-B isolates of different serotypes were selected to assess the different binding properties and receptor usage in CaCo-2 cells, a well-characterized CARpositive and DAF positive polarized cell line with apical and basolateral surfaces. In addition, Trans-Epithelial Electrical Resistance (TEER) measurement, which is indicative of cell integrity and works using the principle that wellformed junctions and healthy membranes have a higher electrical resistance, was carried out. The molecular basis of different binding patterns was also investigated.

\section{Methods}

\section{Cell lines}

CaCo-2 Cell line (human colon adenocarcinoma cell line) was kindly provided by the department of Immunity of mucous membranes and pathogenic agents (GIMAP, Faculty of medicine Jacques Lisfranc, Saint-Etienne, France). These cells were cultured in Dulbecco's Modified Eagle medium (DMEM-F12) (PAA Laboratories) supplemented with 10\% of Fetal Bovine Serum (FBS) (GIBCO) and antibiotic antimycotic solution $1 \times$ (Sigma) containing 100 units $/ \mathrm{ml}$ penicillin, $100 \mu \mathrm{g} / \mathrm{ml}$ streptomycin and $25 \mu \mathrm{g} / \mathrm{ml}$ ciprofloxacin.

$\mathrm{KB}$ cell line (human squamous carcinoma cell line) was grown in RPMI 1640 medium (Sigma) containing 10\% of Fetal Bovine Serum, L-glutamine (2 mM; Sigma) and the same antibiotics. KB cells were used for virus quantification using the $\mathrm{TCID}_{50}$ (tissue culture infectious dose 50\%) method [29] and as controls in the TEER measurements. The cells were incubated at $37^{\circ} \mathrm{C}$ in an atmosphere of $5 \% \mathrm{CO} 2$.

\section{Viruses}

Twenty CV-B clinical isolates of different serotypes (CV-B1 à 6): CV-B1 (CV-B1\#032, CV-B1\#0807, CVB1\#0609), CV-B2 (CV-B2\#N, CV-B2\#37222, CVB2\#0610 M, CV-B2\#2000), CV-B3 (CV-B3\#37335, CV-B3\#523-21, CV-B3\#02), CV-B4 (CV-B4\#N,CVB4\#37428, CV-B4\#07, CV-B4\#0612 and CV-B4-JVB), CV-B5 (CV-B5\#37534, CV-B5\#2003, CV-B5\#99, CVB5\#2000) and CV-B6 (CV-B6\#041) were used. CV-B3 Nancy prototype strain and a recombinant strain (Rec, CV-B3/B4, provided by the Virology Department (GIMAP EA3064) of the Faculty of Medicine of Saint Etienne, France) were tested in parallel. The Rec strain is the first enterovirus derived from interserotypic recombination event occurring in the VP3 coding region and leading to a chimeric CVB3/CV-B4 type. Four subsequent propagations of viruses were performed in $\mathrm{KB}$ cells in a serum-free medium.

\section{Antibodies}

For CAR detection, a monoclonal IgG1 antibody, RmcB (AbCys S.A.) was used. DAF detection was performed using commercially purified mAb, BRIC216 (AbCys S.A), a mouse anti-SCR3 (short consensus repeat 3 of DAF). The amounts of anti-CAR and anti-DAF required to inhibit infection of $\mathrm{CaCo}-2$ cells were titrated by pre-incubation of CV-B-CaCo-2 cells with different concentrations of each antibody from 2 to $10 \mu \mathrm{g}$.

Trans-Epithelial Electrical Resistance (TEER) measurement To establish polarized monolayers, Caco-2 colonic epithelial cells were cultured in (DMEM)-F12 (PAA laboratories) 
with $10 \%$ of Fetal Bovine Serum (GIBCO) on polyester tissue culture inserts (Costar Transwell Clears; 12-mm diameter, $0.4-\mu \mathrm{m}$ pore size) until TEER measurement with an epithelial voltohmmeter (EVOM; World Precision Instruments, Inc.) was stable (300 to $350 \Omega . \mathrm{cm}^{2}$ in 12 to 14 days). For the passage of viruses on $\mathrm{CaCo}-2$ cell line, cells were infected with viruses at MOI $=1$ for $1 \mathrm{~h}$ at room temperature. The monolayer was then washed and incubated at $37^{\circ} \mathrm{C}$. The epithelial voltohmmeter was then used to follow, at various post-inoculation times (pi), the variation of TEER of CaCo- 2 cells along with the viral growth cycle. The TEER measurements were performed first every $30 \mathrm{~min}$ and then every hour until $24 \mathrm{~h}$. KB cells were used as controls in this assay.

\section{Infection and inhibition assays}

CaCo- 2 cells were seeded in 96-well plates. Each plate was pre-treated for $2 \mathrm{~h}$ at $37^{\circ} \mathrm{C}$ with $5 \mu \mathrm{g}$ of $\mathrm{RmcB}$, BRIC216 or a combination of both antibodies. The antibody concentrations used were titrated prior to inhibition analyses. The wells were washed twice with $1 \times$ PBS and viruses $(\mathrm{MOI}=0.01)$ were used to infect the $60 \%$ confluent monolayers. CaCo-2 cells infected in the absence of blocking antibodies are used as control. $200 \mu \mathrm{l}$ serum-free medium were added and the cells were controlled $48 \mathrm{~h}$ post infection for a possible cytopathic effect. $50 \mu \mathrm{l}$ aliquots were also removed $48 \mathrm{~h}$ post infection and $\mathrm{TCID}_{50}$ was determined on KB cells.

\section{RNA extraction and reverse transcription}

Viral RNA was extracted from $100 \mu \mathrm{l}$ of viral supernatant using a QIAamp viral RNA mini kit (QIAGEN, France) according to the manufacturer's recommendations. Ten microliters of extracted RNA were reverse-transcribed into cDNA at $42^{\circ} \mathrm{C}$ for $45 \mathrm{~min}$ using 200 units of SuperScriptIII reverse transcriptase and $2.5 \mathrm{ng} / \mu \mathrm{l}$ of random primers (Invitrogen, Cergy Pontoise, France) in the presence of 10 units of RnaseOUT recombinant RNase inhibitor (Invitrogen, Cergy Pontoise, France).

\section{Amplification experiments}

All the amplification experiments were performed in a Mastercycler gradient thermal cycler (Eppendorf, Hamburg, Germany).

i. VP1 region. Five microliters of cDNA were amplified using $50 \mathrm{pmol}$ of the 292 and 222 primers (Table 1) and 1.25 units of Platinum Taq DNA polymerase (Invitrogen, Cergy Pontoise, France) in $50 \mu \mathrm{l}$ of reaction mixture according to the protocol described by Oberste et al. [30]. A band of the expected size of 357 bp was observed after agarose gel electrophoresis.

ii. VP2 and VP4 regions. Five microliters of cDNA were amplified using $80 \mathrm{pmol}$ of each primer (Table 1) [31] and 1.25 units of Platinum Taq DNA polymerase (Invitrogen, Cergy Pontoise, France) in $50 \mu \mathrm{l}$ of reaction mixture. Some minor modifications were

Table 1 Primers used for the amplification of the $\mathrm{P} 1$ region

\begin{tabular}{|c|c|c|c|c|c|}
\hline Region & Primer & Orientation & Sequence $\left(5^{\prime}-3^{\prime}\right)^{a}$ & Position $^{b}$ & Reference \\
\hline \multirow[t]{2}{*}{ VP1 } & 292 & Sense & MIGCIGYIGARACNGG & $2613-2628$ & 30 \\
\hline & 222 & Antisense & CICCIGGIGGIAYRWACAT & $2969-2951$ & \\
\hline \multirow[t]{2}{*}{ VP2 } & AM12 & Sense & GARGARTGYGGITAYAGYGA & $962-981$ & 31 \\
\hline & AM32 & Antisense & TTDATCCAYTGRTGIGG & $1545-1529$ & \\
\hline \multirow[t]{2}{*}{ VP3 } & $\mathrm{RC7}$ & Sense & GTVHDIAAYGCIGGHATGGG & $1463-1482$ & This study \\
\hline & $\mathrm{RC} 8$ & Antisense & GTYTGCATIGTGTCDSHIGG & $2597-2578$ & \\
\hline \multirow[t]{2}{*}{ VP4 } & $\mathrm{RC} 1$ & Sense & CCATATAGYTATTGGATTGGC & $615-635$ & This study \\
\hline & $\mathrm{RC} 2 \mathrm{M}$ & Antisense & GGIARYTTCCACCACCAHCC & $1197-1178$ & \\
\hline \multirow[t]{9}{*}{ VP1-2A } & $\mathrm{RC} 5 \mathrm{M}$ & Sense & TIACITITGTSATHACIAG & $2799-2817$ & This study \\
\hline & RC6 & Antisense & ACIACRCCYTCICCICCCAT & $3690-3671$ & \\
\hline & $\mathrm{RC} 10$ & Antisense & TCCCACACRCAVYTYWGCC & 3396-3378 & This study \\
\hline & $\mathrm{RC} 5-\mathrm{B} 2$ & Sense & CTAACWITYGTCATNACCAG & $2813-2832$ & This study \\
\hline & RC5-B4 & Sense & CTYACMTITGTSATYACYAG & $2802-2821$ & This study \\
\hline & RC5-B3 & Sense & CTGACGTITGTCATAACAAG & $2798-2817$ & This study \\
\hline & $\mathrm{RC} 5(\mathrm{~B} 5 / \mathrm{B} 6)$ & Sense & GARYTVACYTITGTSATHAC & $2801-2820$ & This study \\
\hline & $\mathrm{RC} 11(\mathrm{~B} 2, \mathrm{~B} 4, \mathrm{~B} 5, \mathrm{~B} 6)$ & Antisense & TCYCTRTTRTARTCYTCCC & 3417-3399 & This study \\
\hline & $\mathrm{RC} 12(\mathrm{~B} 3)$ & Antisense & TCYCTGTTGTAACTITCCC & $3411-3393$ & This study \\
\hline
\end{tabular}

a The following standard ambiguity codes were used: $D=G, A$, or $T ; R=A$ or $G ; Y=T$ or $C ; N=A, T, C$, or $G ; M=A$ or $C ; S=G$ or $C ; H=A, C$ or $T ; W=A$ or $T$ 
made to the amplification program used by Nasri et al. (2007) and included an initial cycle of $95^{\circ} \mathrm{C}$ for $5 \mathrm{~min}, 39$ further cycles of denaturation at $95^{\circ} \mathrm{C}$ for $45 \mathrm{~s}$, annealing at $48^{\circ} \mathrm{C}$ for $45 \mathrm{~s}$ (raised to $50^{\circ} \mathrm{C}$ for VP4 region), extension at $72^{\circ} \mathrm{C}$ for $45 \mathrm{~s}$ and a final extension cycle at $72^{\circ} \mathrm{C}$ for $10 \mathrm{~min}$. The bands of the expected size of $584 \mathrm{bp}$ and $583 \mathrm{pb}$ were respectively observed after electrophoresis in agarose gel.

iii. VP3 and VP1-2A regions. Five microliters of cDNA were amplified using $80 \mathrm{pmol}$ of each primer (Table 1) and 1.25 units of Platinum Taq DNA polymerase (Invitrogen,Cergy Pontoise, France) in $50 \mu \mathrm{l}$ of reaction mixture. The amplification included an initial cycle of $95^{\circ} \mathrm{C}$ for $5 \mathrm{~min} ; 40$ further cycles of denaturation at $94^{\circ} \mathrm{C}$ for $30 \mathrm{~s}$, annealing at $48^{\circ} \mathrm{C}$ for $45 \mathrm{~s}$, extension at $72^{\circ} \mathrm{C}$ for $90 \mathrm{~s}$ and a final extension cycle at $72^{\circ} \mathrm{C}$ for $5 \mathrm{~min}$. The bands of the expected size of $1142 \mathrm{bp}$ and $904 \mathrm{bp}$ were observed respectively. For VP1-2A region, alternative amplification experiments were performed using $80 \mathrm{pmol}$ of the RC5M or RC5 (sense) and RC10 or RC11 and RC12 primers (antisense) (Table 1). The amplification includes the same program of cycles as VP2 region generating a band of $596 \mathrm{pb}$ (using RC5M and $\mathrm{RC} 10$ ) or $600 \mathrm{pb}$ (using RC5/RC11 or RC5/RC12) as expected.

\section{Template purification and sequencing}

To determine the isolates' nucleotide sequences and to identify those amino acid changes in the capsid proteins that could be associated with DAF dependent and independent phenotype, the amplicons were purified using the Montage PCR centrifugal filter devices (Millipore) or a
Qiaquick gel extraction kit (QIAGEN, France), depending on the presence of single or multiple bands, respectively. The purified products of the P1 genomic region were sequenced using $10 \mathrm{pmol} / \mu \mathrm{l}$ of each primer and the GenomeLab Dye Terminator Cycle Sequencing Quick Start kit (Beckman Coulter, Villepinte, France) according to the manufacturer's instructions. The electrophoresis and analysis of DNA sequence reactions were performed with the automated DNA sequencer CEQ8000 (Beckman Coulter, Villepinte, France). The obtained sequences for VP1, VP2, VP3, VP4 and VP1-2A which contain the main antigenic sites of neutralization and cellular attachment receptors were aligned using Clustal W (version 1.81) [32].

\section{Statistical analysis}

Data were analyzed using Student's $t$ test. P values $<0.05$ were considered significant.

\section{Results}

Trans-Epithelial Electrical Resistance (TEER) measurement Polarized monolayers of $\mathrm{CaCo}-2$ cells were cultured in transwell filters until TEER measurement was stable (300 to $350 \Omega . \mathrm{cm}^{2}$ in 12 to 14 days) (Figure 1 ). The KB cells were tested in parallel. When the cells were exposed to virus isolates, a drop in TEER (Figure 2) was evident within $30 \mathrm{~min}$ pi for $\mathrm{CV}-\mathrm{B} 1,3$ and 5 serotypes. The same results were shown for the prototype strain Nancy. However, exposure of CaCo-2 monolayers to a viral isolate that binds CAR but not DAF (CV-B2, CVB4 and CV-B6) had little or no effect on TEER. Interestingly, exposure to the recombinant isolate (Rec, CV-B3/ B4) had the same effect as a CV-B3 isolate on monolayers of $\mathrm{CaCo}-2$ cells. Within 7-11 h after infection, a drop in TEER was observed for all the tested isolates.

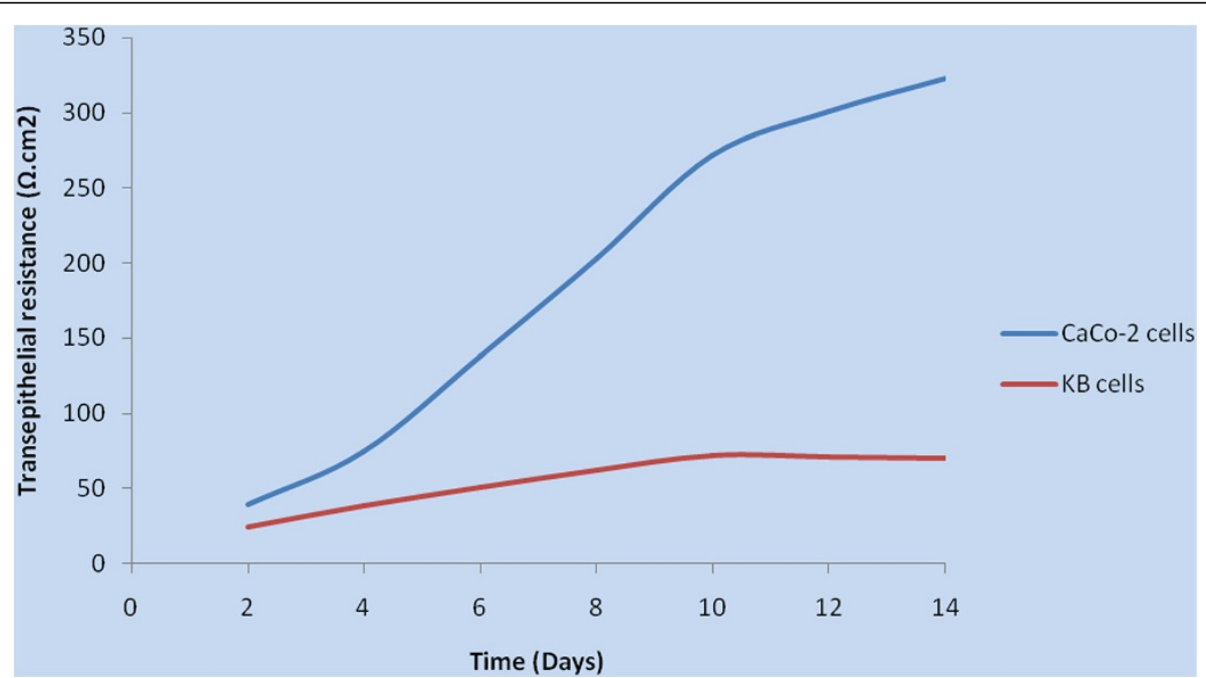

Figure 1 CaCo-2 Trans-Epithelial Electrical Resistance measurements before inoculation with CV-B isolates. 


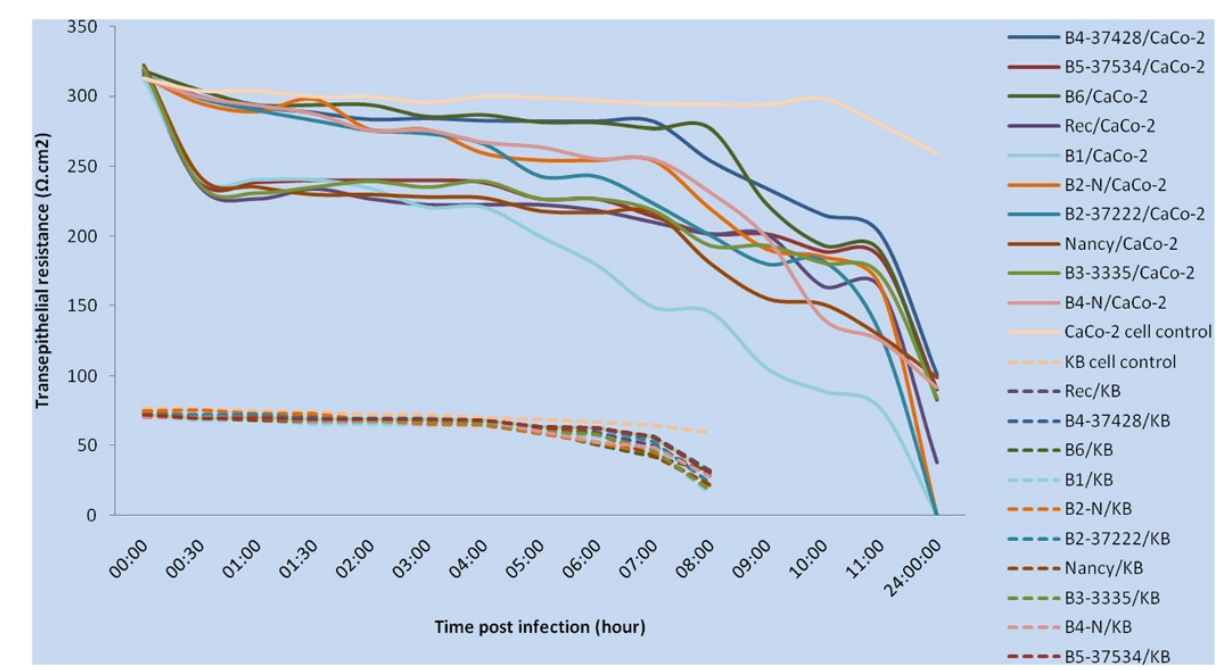

Figure 2 CaCo-2 and KB Trans-Epithelial Electrical Resistance measurements after inoculation with CV-B isolates.

Representative cytogram is depicted in Figure 2. Unlike polarized cells, the loss of membrane integrity in KB cells was not observed (Figure 2).

\section{Infection and inhibition assays}

To further characterize the interaction of clinical isolates of CV-B with CAR/DAF, CV-B binding assays were performed on CaCo-2 cells coexpressing CAR and DAF. $\mathrm{CV}-\mathrm{B}$ binding was assessed by MAb blockade of individual receptors or MAb blockade in combination. CaCo-2 cells infected in the absence of blocking antibodies were used as control (Table 2). All CV-B isolates exhibited high levels of cell lytic activity in the absence of blocking antibodies. Pre-treatment of Caco- 2 cells with anti-CAR monoclonal antibody $\mathrm{RmcB}$ resulted in infection inhibition of all CV-B isolates. Virus titers (expressed in $\mathrm{TCID}_{50}$ ) in cultures treated with $\mathrm{RmcB}$ remained at a low level (Table 2) $(\mathrm{p}<0.05)$. To determine the role of DAF during the virus infection, we used BRIC216, which has been shown to inhibit interaction between CV-B3 and DAF [33]. No inhibition of the replication of CV-B2 (CVB2\#N, CV-B2\#37222, CV-B2\#0610 M, CV-B2\#2000), CVB4 (CV-B4\#N, CV-B4\#37428, CV-B4\#07, CV-B4\#0612 and CV-B4-JVB) and CV-B6 (CV-B6\#041) isolates was observed after pre-treatment of $\mathrm{CaCo}-2$ cells with BRIC216. When the infectious titer of these isolates was measured, titers increased $48 \mathrm{~h}$ post infection to the level comparable with control cells (Table 2). These results imply that DAF is not necessary for the infection by these isolates. Virus attachment was however inhibited by BRIC216 for CV-B1 (CV-B1\#032 and CV-B1\# 0807), CV-B3 (CV-B3\# 523-21 and CV-B3\# 02) and CV-B5 (CV-B5 \#37534 and CVB5\# 2003) isolates. The same result was obtained for the Nancy prototype strain. Similarly, adherence of Rec
Table 2 Virus titers $\left(\mathrm{TCID}_{50} * / 50 \mu \mathrm{l}\right) 48 \mathrm{~h}$ post infection without or in presence of anti-CAR (RmcB), anti-DAF (BRIC 216), or both

\begin{tabular}{lllll}
\hline Isolate & Control (No Ab) & +BRIC216 & + RcmB & RcmB + BRIC216 \\
\hline Nancy & $10^{7.5}$ & $10^{3}$ & $10^{3}$ & $10^{2.5}$ \\
Rec (B3/B4) & $10^{8}$ & $10^{4}$ & $10^{3.7}$ & $10^{2}$ \\
B3-37335 & $10^{7.3}$ & $10^{7}$ & $10^{3}$ & $10^{2}$ \\
B3-523-21 & $10^{7.3}$ & $10^{3.6}$ & $10^{3.5}$ & $10^{2}$ \\
B3-02 & $10^{6.6}$ & $10^{3.9}$ & $10^{3.3}$ & $10^{2}$ \\
B4N & $10^{7}$ & $10^{7}$ & $10^{4}$ & $10^{2}$ \\
B4-37428 & $10^{6.6}$ & $10^{6}$ & $10^{3.3}$ & $10^{3}$ \\
B4 JVB & $10^{7.3}$ & $10^{7}$ & $10^{4}$ & $10^{2.7}$ \\
B4-0612 & $10^{5.3}$ & $10^{5}$ & $10^{3.7}$ & $10^{2}$ \\
B4-07 & $10^{5.3}$ & $10^{5}$ & $10^{3.5}$ & $10^{2}$ \\
B5-37534 & $10^{7}$ & $10^{3}$ & $10^{3}$ & $10^{2}$ \\
B5-2003 & $10^{8}$ & $10^{4.9}$ & $10^{3}$ & $10^{2}$ \\
B5-99 & $10^{6.33}$ & $10^{6}$ & $10^{3}$ & $10^{2}$ \\
B5-2000 & $10^{7.3}$ & $10^{7}$ & $10^{4}$ & $10^{2}$ \\
B6-041 & $10^{5.9}$ & $10^{5}$ & $10^{3.5}$ & $10^{2}$ \\
B2-37222 & $10^{6.3}$ & $10^{6}$ & $10^{4}$ & $10^{2.5}$ \\
B2N & $10^{6}$ & $10^{6}$ & $10^{3.5}$ & $10^{2.5}$ \\
B2-0610 M & $10^{5.3}$ & $10^{5}$ & $10^{3}$ & $10^{2}$ \\
B2-2000 & $10^{6.3}$ & $10^{6}$ & $10^{4}$ & $10^{2.7}$ \\
B1-032 & $10^{7.6}$ & $10^{3.9}$ & $10^{3}$ & $10^{3}$ \\
B1-0609 & $10^{6.3}$ & $10^{6}$ & $10^{3}$ & $10^{2}$ \\
B1-0807 & $10^{7.6}$ & $10^{4}$ & $10^{3}$ & $10^{2}$ \\
\hline
\end{tabular}

(*) TCID50: 50\% Tissue Culture Infective Dose. $\mathrm{Ab}$ antibodies. 
CV-B3/B4 isolate to $\mathrm{CaCo}-2$ cells was significantly reduced in the presence of BRIC216 antibody. Productivity of infection was by $10^{3}$ and $10^{4}$-fold lower than measured on control cells $(\mathrm{p}<0.05)$. Interestingly, 4 clinical $\mathrm{CV}-\mathrm{B}$ isolates (CV-B3\#37335, CV-B1\#0609, CV-B5\#99 and CV-B5\#2000) were capable of lytically infecting the $\mathrm{CaCo}-2$ cells in the presence of anti-DAF mAb. They were still able to efficiently replicate in Caco-2 cells, giving rise to the same amount of viral progeny than the control indicating an alternative attachment to $\mathrm{Ca}-\mathrm{Co} 2$ cells. Finally, by combining anti-DAF and anti-CAR antibodies, viral attachment was significantly reduced and virus titers remained at a low level.

\section{Sequence analysis}

Since CV-B isolates examined herein exhibited a strong CAR attachment- phenotype and for some isolates, either a DAF attachment phenotype or another unidentified phenotype, we speculate that they accumulated some amino acid differences. Comparison of the sequences of CV-B isolates revealed significant differences (Additional file 1). Previously, two residues 138D in VP2, and 234Q in VP3, had been identified as necessary for CV-B infection [34]. We have questioned if the attachment of these isolates in CAR-expressing cells is indeed due to the presence of these changes in amino acids and account for DAF attachment. We also tried to determine if there were perhaps other key residues associated with their phenotypes. Interestingly, we found that the Nancy strain has the two key residues associated with DAF-binding, the VP2-138 and the VP3-234. However, for the other isolates, there is DAF dependent isolates with "D" amino acid but also DAF independent isolates with the same amino acid in the position VP2-138. In addition, in the position VP3234, we have DAF dependent isolates with "Q" and " $D$ " amino acids versus DAF independent isolates with " $Q$ ", " $\mathrm{D}$ " and " $\mathrm{T}$ " amino acids. In addition, when looking for other possible key residues that could be implicated in the DAF binding, we find that in position VP2-114, there's the "K" amino acid (Lysin) for all the DAF dependent isolates in comparison with DAF independent isolates ( $\mathrm{S} / \mathrm{H}$ amino acids).

\section{Discussion and conclusions}

Many viruses use multiple receptors to attach and enter susceptible target cells $[16,35,36]$. In addition, cellular receptor usage differs significantly between clinical isolates. Notably CV-B clinical isolates exhibit differences in their interactions with cell surface-expressed DAF [23]. DAF may sequester $\mathrm{CV}$-B to the cell surface and maintain it in a conformationally unaltered state for subsequent interactions with CAR that induce capsid conformational changes and cell entry [24,37].

As a first step in the current study, the experiments were performed to assess the interactions of CV-B clinical isolates with DAF and CAR. Cell pre-treatment with $\mathrm{RmcB}$ resulted in a marked inhibition of all tested $\mathrm{CV}-\mathrm{B}$ isolates. $\mathrm{CaCo}-2$ infection by $\mathrm{CV}-\mathrm{B}$ isolates was then clearly mediated by binding of the virus to CAR, to which Rmcb provided an effective blockade. All tested $\mathrm{CV}-\mathrm{B}$ isolates show an absolute requirement for CAR but vary in their binding to DAF. The collected time points were titrated on KB cells (Table 2). The low titers obtained after $48 \mathrm{~h}$ are likely to be due to viral binding to regenerated CAR, no longer blocked by the antibody. These results support the virus usage of CAR when expressed on $\mathrm{CaCo}-2$ cells, and indicate that binding to CAR is necessary to establish an efficient infection [23-26,28,38]. To determine the role of DAF during infection, we used BRIC216, which has been shown to inhibit interaction between CV-B3 and DAF [33]. The results implied that DAF was not necessary for CV-B2, $\mathrm{CV}-\mathrm{B} 4$ and $\mathrm{CV}-\mathrm{B} 6$ isolates. These viruses interact with the receptor (CAR), attach to and infect $\mathrm{CaCo}-2$ cells. These results are in accordance with many previously published reports $[12,23,38]$. These isolates could also bind DAF with a lower affinity or bind another SRC than CV-B1, CV-B3 and CV-B5 DAF-binding strains. However, DAF was used by some isolates of CV-B1, CV-B3, and CV-B5. DAF was also used by the Nancy strain which is in contradiction with some studies [26,34]. A study of receptor preference in clinical CV-B1-5 isolates showed DAF binding viruses among CV-B1, 3 and 5, but not among the CV-B2 or CV-B4 isolates which have never been reported to use any other receptor but CAR. Interestingly, the Rec isolate (CV-B3/B4) was a DAF-dependent isolate behaving as a CV-B3 rather than a CV-B4 which raises the hypothesis that binding to DAF is the most adaptable way for infection. By molecular typing, the Rec isolate was identified as CV-B3 in the VP2 region and CVB4 in the VP1 region, suggesting the occurrence of an interserotypic recombination event in the capsid region. The nucleotide sequence analysis of the whole structural genomic region showed the occurrence of a recombination event at position 1950 within the VP3 capsid gene, in a region coding for the $2 \mathrm{~b}$ antigenic site previously described for CV-B3. Interestingly, the strain was neutralized by a polyclonal CV-B3-specific antiserum but not by a CVB4-specific antiserum. The neutralization pattern suggests that the major antigenic site is located within the VP2 protein [39].

Taken together, these results suggest that even within a single serotype, viruses interact differently with cellular receptors. A synergistic inhibitory effect of anti-DAF and anti-CAR antibodies was observed with regard to infection which is in accordance with previous studies [40]. Antibody-mediated blockade showed that the presence of mAbs to both DAF and CAR was required to effect total inhibition of lytic infection. 
In the present study, we also report the capacity of some clinical CV-B isolates not to utilize DAF interactions in a functional role. These isolates infect cells using either only CAR receptor or another co-receptor other than DAF. They may have adapted to utilize a novel as-yetunidentified receptor present on $\mathrm{CaCo}-2$ cells, thereby allowing virus attachment. If so, it is likely that the virus has only low affinity for this additional receptor, as most strains utilize DAF. A variant of CV-B3 has been shown to interact with heparan sulfate (HS) at the cellular surface [41]. HS has also been recognized as a receptor of many different viruses allowing initial binding to the cell surface including echoviruses, theilers murine encephalomyelitis virus, and foot-and-mouth disease virus $[15,42,43]$. HS seems to be a possible candidate that could be a coreceptor mediating the binding of these $\mathrm{CV}-\mathrm{B}$ isolates to the cell surface. But, in cell entry, what is the role of virus binding to a likely low-affinity receptor? Some investigations are currently conducted into these matters. Receptor binding can vary among CV-B isolates, and may evolve within infected tissues or cultured cells [24]. Variants with altered co-receptor may arise spontaneously, either in the body or in tissue culture, and interaction with cells that do or do not express receptor molecules may exert powerful selective pressures on a virus population. Interaction between CV-B and their cell surface receptors appear then to be quite complex.

As a second step of the current study, the variation of the TEER of Caco- 2 cells along with the viral growth cycle was followed at various times. Similarly to the results reported by Coyne and Bergelson (2006) [38], a drop in TEER (Figure 2) was evident within $30 \mathrm{~min}$ p.i for CV-B1, 3 and 5 serotypes and Rec isolate (CV-B3/B4) suggesting a transient partial loss of junctional integrity during early stages of virus entry, specifically when the virus had formed DAF clusters and was beginning to relocalize to the tight junctions (TJ). By binding to the CAR extracellular domain, CV-B may interfere with CAR-CAR interactions that are thought to contribute to junctional stability. Exposure of CaCo-2 monolayers to a viral isolate that binds CAR but not DAF (CV-B2, CV-B4 and CV-B6) had little or no effect on TEER, as reported by Shieh and Bergelson (2002) [13]. These viruses may avoid the barrier imposed by the tight junction by passing through $M$ cells to reach submucosal lymphoid tissue. Within 7-11 h after infection, a drop in TEER was observed in all the tested isolates demonstrating the arrival to the final stages of the viral growth cycle and cell lysis (Figure 2). When polarized epithelial cells that express CAR in cell-cell junctions were found to be somewhat resistant to infection, but less resistant to $\mathrm{CV}-\mathrm{B}$ that bind DAF as well as CAR, the relevance of DAF-binding CV-B strains was established [13,14].

Finally, in an attempt to gain a better understanding of the molecular basis of CV-B cellular interactions, the P1 region was sequenced and aligned. The data presented in this study estimated that in vitro selection of different phenotypes, may lead to the acquisition of amino acid mutations in the viral capsid proteins, thereby allowing the use of different and additional binding molecules. Surprisingly, some differences in the deduced amino acid sequences between clinical $\mathrm{CV}$-B isolates were revealed (Additional file 1). Previously, Pan J et al. (2011) [34] produced cDNA clones encoding both CV-B3-RD and CV-B3-Nancy. They found that a single amino acid change, the replacement of a glutamate within VP3 (VP3-234E) with a glutamine residue derived from CV-B3-RD (VP3234Q), confers upon CV-B3-Nancy the capacity to bind DAF and to infect RD cells. Furthermore, when CV-B3$\mathrm{H} 3$ - an isolate that does not bind to DAF although it already possesses VP3-234Q - was passed on RD cells, they obtained a DAF-binding isolate with a single amino acid change within VP2 (VP2-138 N to D). They conclude that both VP3-234Q and VP2-138D are required for virus attachment to DAF. In our study, we have questioned whether VP2-138D and VP3-234Q account for the CV-B phenotype DAF dependent (Additional file 1). In parallel, we tried to determine if there were perhaps other key residues associated with DAF binding. Interestingly, we found that the Nancy strain has the two key residues associated with DAF-binding, the VP2-138D and the VP3-234Q. However, for the other isolates, there is DAF dependent isolates with " $\mathrm{D}$ " amino acid but also DAF independent isolates with this amino acid. In addition, in the position VP3-234, we found DAF dependent isolates with "Q" and " $D$ " amino acid versus DAF independent isolates with " $Q$ ", " $D$ " and " $T$ " amino acids. Interestingly, when looking for other possible key residues that could be implicated in the DAF binding, we find that in position VP2-114 (Additional file 1), there's a "K" amino acid (Lysin) common for all the DAF dependent isolates in comparison with DAF independent isolates ( $\mathrm{S} / \mathrm{H}$ amino acids). The structure of the CV-B-DAF complex determined by cryo-electron microscopy is then needed to confirm if VP2-114 K is in contact with DAF. When Lindberg et al. [44] constructed a series of genomic Chimeras between CV-B3-RD and a CV-B3-Nancy isolate (a strain that not binds DAF), they identified a genome segment that conferred the capacity to infect and kill RD cells efficiently-a phenotype that likely depends on, but is not necessarily synonymous with, DAF binding. Within this segment (which encodes VP2 and a part of VP3), the wild-type and RD isolates differed at two sites: in RD, a serine was substituted for threonine at position 151 within VP2 (VP2-151S) and a valine was substituted for aspartate at VP2 position 108 (VP2-108 V) but, neither VP2-151S nor VP2-108 V was found to be in contact with DAF.

In the light of these data, it is clear that multiple surface residues participate in binding DAF. So, the presence of 
138D, 234Q or 114 K may contribute for DAF binding, but it does not suggest that they are necessary neither sufficient. Interaction between CV-B and their cell surface receptors appear then to be more complex. However, while not addressed in the present study, the involvement of additional changes located at other regions of the viral genome (e.g., 5_-untranslated region) cannot be ruled out. Further studies are presently underway to provide a better molecular understanding of theses phenotypes and determine the impact of receptor variation for infection and pathogenesis in vivo.

The present results indicate, moreover, that in some circumstances, DAF binding could not be used for some CVB isolates and to conclude, CV-B (at least CV-B1, 3 and 5) might be subdivided into two generalized DAFbinding phenotypes: $\mathrm{CV}$-B that do not bind to DAF (which apparently includes most of all CV-B2, 4, and 6, as well as some isolates of CV-B1, 3 and 5) and CV-B that bind to DAF but require CAR for infection.

\section{Additional file}

\section{Additional file 1: The solid vertical lines delineate the four} structural viral proteins (VP). The antigenic sites described for CV-B3 by Auvinen et al. [45] are depicted in gray line and designated according to the nomenclature of those authors. The asterisks design sequence homologies, the signs «. » and ":" design amino acid differences. Regarding positions exhibiting amino acid differences or homologies between the two phenotypes, blue vertical line locates CV-B surface residues predicted to interact with DAF, VP2-138 and VP3-234. Yellow vertical line locates other CVB surface residues that could interact with DAF, VP2-114 K. The amino acids are numbered according to the sequence of the reference strain of CV-B3 (accession number M16572). The positions of the main tertiary structures described for CV-B3 [46] are indicated by double-headed horizontal arrows above the sequences. Sequence alignments were generated by using the Clustal W (version 1.81) program [32]

\section{Abbreviations}

Ab: Antibody; CAR: Coxsackievirus adenovirus receptor; CV-B: Coxsackie B viruses; DAF: Decay accelerating factor; mAb: monoclonal antibody; pi: post infection; Rec: Recombinant isolate; SCR: Short consensus repeat:; $\mathrm{TCID}_{50}$ : Tissue culture infectious dose 50\%; TEER: Trans-Epithelial Electrical Resistance.

\section{Competing interests}

The authors declare that they have no competing interests.

\section{Authors' contributions}

RS Carried out the molecular methods, the analysis and interpretation of these data and drafted the manuscript; HR carried out the TEER measurements; Gl carried out the cell culture and helped to draft the manuscript; DN and SP carried out the conception of the primers; LB and SP participate in the alignment of sequences; PB and AM carried out the correction of the manuscript; $P B$ is the director of this work and responsible for the general supervision of the research group. All authors read and approved the final manuscript.

\section{Author details}

${ }^{1}$ Laboratory of Transmissible Diseases LR99-ES27, Faculty of Pharmacy, Avenue Avicenne 5000, Monastir, Tunisia. ${ }^{2}$ Laboratory of Bacteriology-Virology, GIMAP EA3064, Faculty of Medicine of Saint-Etienne, Saint-Etienne, France. ${ }^{3}$ Laboratory of Bio-Active Substances, Center of Biotechnology of Borj Cedria, Borj Cedria,
Tunisia. ${ }^{4}$ Laboratory of Bacteriology-Virology-Hygiene, University Hospital Saint-Etienne, Saint-Etienne, France.

Received: 21 January 2014 Accepted: 6 May 2014

Published: 21 May 2014

\section{References}

1. Klingel K, Hohenadl C, Canu A, Albrecht M, Seemann M, Mall G, Kandolf R: Ongoing enterovirus-induced myocarditis is associated with persistent heart muscle infection: quantitative analysis of virus replication, tissue damage, and inflammation. PNAS USA 1992, 89:314-318.

2. Klingel $K$, Rieger $P$, Mall G, Selinka HC, Huber M, Kandolf R: Visualization of enteroviral replication in myocardial tissue by ultrastructural in situ hybridization: identification of target cells and cytopathic effects. Lab Invest 1998, 78:1227-1237.

3. Fohlman J, Friman G: Is juvenile diabetes a viral disease? Ann Med 1993, 25:569-574.

4. Polacek C, Lundgren A, Andersson A, Lindberg AM: Genomic and phylogenetic characterization of coxsackievirus B2 prototype strain Ohio-1. Virus Res 1999 , 59:229-238.

5. Rueckert RR: Picornaviridae: The Viruses and Their Replication. In Fields Virology. 3rd edition. Edited by Fields BM, Knipe DM, Howley PM. Philadelphia: Lippincott-Raven Publishers; 1996:609-654.

6. Rossmann MG: The canyon hypothesis. Hiding the host cell receptor attachment site on a viral surface from immune surveillance. $J$ Biol Chem 1989, 264:14587-14590.

7. Rossmann MG, Arnold E, Erickson JW, Frankenberger EA, Griffith JP, Hecht HJ, Johnson JE, Kamer G, Luo M, Mosser AG, Rossmann MG, Arnold E, Erickson JW, Frankenberger EA, Griffith JP, Hecht HJ, Johnson JE, Kamer G, Luo M, Mosser AG, Rueckert RR, Sherry B, Vriend G: Structure of a human common cold virus and functional relationship to other picornaviruses. Nature (London) 1985, 317:145-153.

8. Rossmann MG: The canyon hypothesis. Viral Immunol 1989, 2:143-161.

9. He Y, Chipman PR, Howitt J, Bator CM, Whitt MA, Baker TS, Kuhn RJ, Anderson CW, Freimuth P, Rossmann MG: Interaction of coxsackievirus B3 with the full length coxsackievirus-adenovirus receptor. Nat Struct Biol 2001, 8:874-878.

10. Fanning AS, Mitic LL, Anderson JM: Transmembrane proteins in the tight junction barrier. J Am Soc Nephrol 1999, 10:1337-1345.

11. Philipson L, Pettersson RF: The coxsackie-adenovirus receptor-a new receptor in the immunoglobulin family involved in cell adhesion. Curr Top Microbiol Immunol 2004, 273:87-111.

12. Polacek C, Ekstr"om JO, Lundgren A, Lindberg AM: Cytolytic replication of coxsackievirus B2 in CAR-deficient rhabdomyosarcoma cells. Virus Res 2005, 113:107-115.

13. Shieh JT, Bergelson JM: Interaction with decay-accelerating factor facilitates coxsackievirus B infection of polarized epithelial cells. J Virol 2002, 76:9474-9480.

14. Cohen CJ, Shieh JT, Pickles RJ, Okegawa T, Hsieh JT, Bergelson JM: The coxsackievirus and adenovirus receptor is a transmembrane component of the tight junction. Proc Natl Acad Sci U S A 2001, 98:15191-15196.

15. Goodfellow IG, Evans DJ, Blom AM, Kerrigan D, Miners JS, Morgan BP, Spiller OB: Inhibition of Coxsackie B virus infection by soluble forms of its receptors: binding affinities, altered particle formation, and competition with cellular receptors. J Virol 2005, 79:12016-12024.

16. Shafren DR, Bates RC, Agrez MV, Herd RL, Burns GF, Barry RD: Coxsackieviruses B1, B3, and B5 use decay accelerating factor as a receptor for cell attachment. J Virol 1995, 69:3873-3877.

17. Bergelson JM, Mohanty JG, Crowell RL, St John NF, Lublin DM, Finberg RW: Coxsackievirus B3 adapted to growth in RD cells binds to decay-accelerating factor (CD55). J Virol 1995, 69:1903-1906.

18. Hafenstein S, Bowman VD, Chipman PR, Bator Kelly CM, Lin F, Medof ME, Rossmann MG: Interaction of decay-accelerating factor with coxsackievirus B3. J Virol 2007, 81(23):12927-12935.

19. Williams P, Chaudhry Y, Goodfellow IG, Billington J, Powell R, Spiller OB, Evans DJ, Lea S: Mapping CD55 function. The structure of two pathogen-binding domains at 1.7 A. J Biol Chem 2003, 278:10691-10696.

20. Bergelson JM, Chan M, Solomon KR, St. John NF, Lin H, Finberg RW: Decay-accelerating factor (CD55), a glycosylphosphatidylinositol-anchored complement regulatory protein, is a receptor for several echoviruses. Proc Natl Acad Sci U S A 1994, 91:6245-6249. 
21. Karnauchow TM, Tolson DL, Harrison BA, Altman E, Lublin DM, Dimock K The HeLa cell receptor for enterovirus 70 is decay-accelerating factor (CD55). J Virol 1996, 70:5143-5152.

22. Shafren DR, Dorahy DJ, Ingham RA, Burns GF, Barry RD: Coxsackievirus A21 binds to decay-accelerating factor but requires intercellular adhesion molecule-1 for cell entry. J Virol 1997, 71:4736-4743.

23. Bergelson JM, Modlin JF, Wieland-Alter W, Cunningham JA, Crowell RL, Finberg RW: Clinical coxsackievirus B isolates differ from laboratory strains in their interaction with two cell surface receptors. J Infect Dis 1997, 175:697-700.

24. Bergelson JM, Cunningham JA, Droguett G, Kurt-Jones EA, Krithivas A, Hong JS, Horwitz MS, Crowell RL, Finberg RW: Isolation of a common receptor for coxsackie B viruses and adenoviruses 2 and 5. Science 1997 275:1320-1323.

25. Martino TA, Petric M, Weingartl $H$, Bergelson JM, Opavsky MA, Richardson CD, Modlin JF, Finberg RW, Kain KC, Willis N, Gauntt CJ, Liu PP: The coxsackieadenovirus receptor (CAR) is used by reference strains and clinical isolates representing all six serotypes of coxsackievirus group $B$ and by swine vesicular disease virus. Virology 2000, 271:99-108.

26. Shafren DR, Williams DT, Barry RD: A decay accelerating factor-binding strain of coxsackievirus $B 3$ requires the coxsackievirus \pm adenovirus receptor protein to mediate lytic infection of rhabdomyosarcoma cells. J Virol 1997, 71:9844-9848.

27. Fricks CE, Hogle JM: Cell-induced conformational change in poliovirus: externalization of the amino terminus of VP1 is responsible for liposome binding. J Virol 1990, 64:1934-1945

28. Milstone AM, Petrella JE, Sanchez MD, Mahmud M, Whitbeck JC, Bergelson JM: Interaction with Coxsackievirus and Adenovirus Receptor, but Not with Decay-Accelerating Factor (DAF), Induces A-Particle Formation in a DAF-Binding Coxsackievirus B3 Isolate. J Virol 2005, 79:655-660.

29. Reed $L$, Muench $M$ : A simple method for estimating fifty percent endpoints. Am J Hyg 1938, 27:493-497.

30. Oberste MS, Nix WA, Maher K, Pallansch MA: Improved molecular identification of enteroviruses by RT-PCR and amplicon sequencing. J Clin Virol 2003, 26(3):375-377.

31. Nasri D, Bouslama L, Omar S, Saoudin H, Bourlet T, Aouni M, Pozzetto B, Pillet S: Typing of human enterovirus by partial sequencing of VP2. J Clin Microbiol 2007, 45(8):2370-2379.

32. Thompson JD, Higgins DG, Gibson TJ: CLUSTAL W: improving the sensitivity of progressive multiple sequence alignment through sequence weighting, position-specific gap penalties and weight matrix choice. Nucleic Acids Res 1994, 22:4673-4680.

33. Martino TA, Petric M, Brown M, Aitken K, Gauntt CJ, Richardson CD, Chow LH, Liu PP: Cardiovirulent coxsackieviruses and the decay-accelerating factor (CD55) receptor. Virology 1998, 244:302-314.

34. Pan J, Narayanan B, Shah S, Yoder JD, Cifuente JO, Hafenstein S, Bergelson JM: Single amino acid changes in the virus capsid permit coxsackievirus B3 to bind decay-accelerating factor. J Virol 2011, 85:7436-7443.

35. Schneider-Schaulies J, Dunster LM, Schwartz-Albiez R, Krohne G, ter Meulen V Physical association of moesin and CD46 as a receptor complex for measles virus. J Virol 1995, 69:2248-2256.

36. Triantafilou K, Fradelizi D, Wilson K, Triantafilou M: GRP78, a coreceptor for coxsackievirus $A 9$, interacts with major histocompatibility complex class molecules which mediate virus internalization. J Virol 2002, 76:633-643.

37. Freimuth P, Philipson L, Carson SD: The coxsackievirus and adenovirus receptor. Curr Top Microbiol Immunol 2008, 323:67-87.

38. Coyne CB, Bergelson JM: Virus-Induced Abl and Fyn Kinase Signals Permit Coxsackievirus Entry through Epithelial Tight Junctions. Cell 2006, 124:119-131.

39. Bouslama L, Nasri D, Chollet L, Belguith K, Bourlet T, Bouslama L, Nasri D, Chollet L, Belguith K, Bourlet T, Aouni M, Pozzetto B, Pillet S: Natural recombination event within the capsid genomic region leading to a chimeric strain of human enterovirus B. J Virol 2007, 81:8944-8952.

40. Pasch A, Küpper JH, Wolde A, Kandolf R, Selinka HC: Comparative analysis of virus-host cell interactions of haemagglutinating and nonhaemagglutinating strains of coxsackievirus B3. J Gen Virol 1999, 80:3153-3158

41. Zautner AE, Korner U, Henke A, Badorff C, Schmidtke M: Heparan sulfates and coxsackievirus-adenovirus receptor: each one mediates coxsackievirus B3 PD infection. J Virol 2003, 77(18):10071-10077.
42. Jackson T, Ellard FM, Ghazaleh RA, Brookes SM, Blakemore WE, Corteyn AH, Stuart DI, Newman JW, King AM: Efficient infection of cells in culture by type $\mathrm{O}$ foot-and-mouth disease virus requires binding to cell surface heparan sulfate. J Virol 1996, 70:5282-5287.

43. Goodfellow IG, Sioofy AB, Powell RM, Evans DJ: Echoviruses bind heparan sulfate at the cell surface. J Virol 2001, 75:4918-4921.

44. Lindberg AM, Crowell RL, Zell R, Kandolf R, Pettersson U: Mapping of the RD phenotype of the Nancy strain of coxsackievirus B3. Virus Res 1992, 24:187-196

45. Auvinen P, Makela MJ, Roivainen M, Kallajoki M, Vainionpaa R, Hyypia T: Mapping of antigenic sites of coxsackievirus B3 by synthetic peptides. APMIS 1993, 101:517-528.

46. Muckelbauer JK, Kremer M, Minor P, Diana G, Dutko FJ, Groarke J, Pevear DC, Rossmann MG: The structure of coxsackievirus B3 at $3.5 \AA$ resolution. Structure 1999, 53:653-667.

doi:10.1186/1423-0127-21-50

Cite this article as: Riabi et al:: Study of Coxsackie B viruses interactions with Coxsackie Adenovirus receptor and Decay-Accelerating Factor using Human CaCo-2 cell line. Journal of Biomedical Science 2014 21:50.

\section{Submit your next manuscript to BioMed Central and take full advantage of:}

- Convenient online submission

- Thorough peer review

- No space constraints or color figure charges

- Immediate publication on acceptance

- Inclusion in PubMed, CAS, Scopus and Google Scholar

- Research which is freely available for redistribution 